\title{
Identification and quantification of selected metabolites in differently pigmented leaves of lettuce (Lactuca sativa L.) cultivars harvested at mature and bolting stages
}

\author{
Awraris Derbie Assefa', Susanna Choi ${ }^{1}$, Jae-Eun Lee ${ }^{1}$, Jung-Sook Sung ${ }^{1}$, On-Sook Hur ${ }^{1}$, Na-Young Ro ${ }^{1}$,
} Ho-Sun Lee ${ }^{1}$, Suk-Woo Jang ${ }^{2}$ and Ju-Hee Rhee ${ }^{\text {* }^{*}}$

\begin{abstract}
Background: Identification and screening of cultivars rich in bioactive phytoconstituents can be potentially useful to make nutrient-dense dishes and in medicinal formulations. In this study, we have identified, characterized and quantified caffeoylquinic acids, dicaffeoylquinic acid, dicaffeoyltartaric acid, kaempferol conjugates, quercetin malonylglucoside, sesquiterpene lactones, and cyanidin in 22 lettuce cultivars at mature and bolting stages using UPLC-PDA-QTOF-HDMS, UPLC, and HPLC.

Results: The composition and contents of the studied metabolites and antioxidant activity varied significantly and depend on leaf color, cultivar type and stage of maturity. The main phenolic acid components of lettuce were quinic and tartaric acid derivatives, whereas kaempferol derivatives were the dominant flavonoids. The sum of the content of phenolic acids ranged from 18.3 to $54.6 \mathrm{mg} / 100 \mathrm{~g}$ DW and 15.5 to $54.6 \mathrm{mg} / 100 \mathrm{~g} \mathrm{DW}$, whereas the sum of the contents of flavonoids ranged from 9.2 to $25.9 \mathrm{mg} / 100 \mathrm{~g} \mathrm{DW}$ and 14.9 to $83.0 \mathrm{mg} / 100 \mathrm{~g}$ DW in mature and bolting stage cultivars, respectively. The content of cyanidin, lactucin, lactucopicrin, and ABTS radical antioxidant activity were in the range of 0.3 to 9.7 (mature stage) and 0.5 to $10.2 \mathrm{mg} / \mathrm{g}$ DW (bolting stage), 1.8 to 41.9 (mature stage) and 9.7 to 213.0 (bolting stage) $\mu \mathrm{g} / \mathrm{g} \mathrm{DW}, 9.9$ to 344.8 (mature stage) and 169.2 to 3888.2 (bolting stage) $\mu \mathrm{g} / \mathrm{g}$ DW, and 12.1 to 29.0 (mature stage) and 15.7 to 30.3 (bolting stage) mg TE/g DW, respectively. The principal component analysis (PCA) showed that the green and red pigmented lettuce cultivars were grouped to the negative and positive sides of PC1, respectively, while the green/red pigmented cultivars were distributed throughout the four quadrants of the PCA plots with no prominent grouping. The loading plot showed that phenolic acids, flavonoids, and cyanidin are the most potent contributors to the radical scavenging activity of lettuce extracts.
\end{abstract}

Conclusions: Lettuce at the bolting stage accumulate relatively high amount of sesquiterpene lactones (SLS), quercetin malonylglucoside (QMG), methylkaempferol glucuronide (MKGR), kaempferol malonylglucoside (KMG), and 3-O-caffeoylquinic acid (3-CQA) compared to the mature stage. Higher amount of phytoconstituents were found to be accumulated in the red pigmented lettuce leaves compared to the green lettuce leaves. In addition, the contents of most of the metabolites in lettuce seem to increase with age of the leaves. The presence of the two bitter SLs, lactucin and lactucopicrin, in significantly high amount in lettuce leaves at bolting stage could diminish consumer acceptance. However, alternatively, these leaves could be utilized by nutraceutical companies working to recover these compounds. Keywords: Lettuce, ABTS. ${ }^{+}$, Anthocyanins, Sesquiterpene lactones, Phenolic acids, Flavonoids

\footnotetext{
*Correspondence: rheehk@korea.kr

${ }^{1}$ National Agrobiodiversity Center, National Institute of Agricultural Sciences, RDA, Jeonju 54874, South Korea

Full list of author information is available at the end of the article
} 


\section{Introduction}

Lettuce, one of the most popular vegetables in terms of production and economic value, ranks second to potato in per capita consumption [1]. It is planted annually in backyards, containers, shade net, and greenhouses even through hydroponics with a range of environmental conditions. Lettuce is an important crop because of its increased productivity per unit area of cultivated land and its suitability in vertical farming systems [2]. Lettuce cultivar type could be classified based on head shape such as crisphead, butterhead, cos (romaine), and leafy. It is usually grown for its leaf, but sometimes for its stem and seeds. In Korea, lettuce is mainly consumed as a salad dish or eaten with sandwiches and meat [3]. In recent years, consumers' interest in lettuce has increased dramatically due to its attractive visual quality, minimum microbial load, and presence of nutritionally important phytoconstituents [1]. Moreover, lettuce contains several bioactive phytochemicals including, anthocyanins [4], phenolic acids [5, 6], flavonoids [5, 7], carotenoids, folate, ascorbic acid [8], and sesquiterpene lactones [3, 9]. In addition, lettuce plants did show potent allelopathic activity [10].

The composition of phytochemicals in lettuce could be affected by several factors such as genetic makeup, mulching, and storage conditions [11, 12], planting date $[4,13]$, temperature [14], processing [12], leaf position, and head formation stage [15], type (leaf/head/romaine) [16], and harvesting stage [11, 17]. On the other hand, allelopathic effects of lettuce which could be due to their sesquiterpene lactones content vary depending on the type of cultivar [10]. Lettuce leaf color is an important factor not only because it is the first trait that registers with consumers/buyers but also it indicates the presence/absence of some beneficial metabolites to the plant and human health $[1,6]$. Obviously, lettuce at the bolting stage is more exposed to environmental conditions (nutrient absorptions, temperature, humidity, and light) compared to mature stage due to a longer period of cultivation. Hence, one would expect a biochemical conversion, degradation, or accumulation throughout the growing season.

Lettuce goes through distinct growth stages including, emergence of cotyledons leaves, formation of distinct circular cluster of leaves (rosette stage), inward curling of tips of inner leaves (cupping stage), overlapping of the cupped leaves and covering the growing point of the plant (heading stage), maturing where head/leaf reaches marketable size, and finally bolting where the main shoot inside head begins to elongate. To date, studies on the lettuce composition of phenolic compounds and its potential as antioxidant were focused on baby-leaf and mature stages of lettuce $[1,8,18,19]$. For example, Kim et al. [1] studied the carotenoids, cyanidin, fatty acids, and total folate profiles of 23 cultivars of baby-leaf lettuce only. Studies on the composition of sesquiterpene lactones and anthocyanin content in the leaves of lettuce at different stages of various types of lettuce are elusive. Thus, in this study, the profiles of phenolic acids, flavonoids, anthocyanidins, sesquiterpene lactones and antioxidant activity in leaves of lettuce cultivars at the mature and bolting stages of lettuce were examined. Also, it is discussed how the lettuce phytochemicals are affected by genotype, leaf color, and maturity. The obtained quantitative data were analyzed using principal component analysis (PCA) to distinguish the studied cultivars based on their leaf color. The knowledge on the phytochemicals distribution in differently pigmented lettuce cultivars at mature and bolting stages could be of interest to consumers and food industry especially in selecting suitable cultivar and stage of development to make lettuce related nutrientdense dishes and to extract health promoting phytochemicals that could potentially be useful in medicinal formulations.

\section{Materials and methods \\ Chemicals, reagents, and standards}

All chemicals and solvents used in extraction and analysis were of analytical grade and purchased from Fisher Scientific Korea Ltd. (Seoul, South Korea) and Sigma-Aldrich (St. Louis, MO, USA). Standards lactucin, lactucopicrin, kuromanin chloride (cyanidin 3-O-glucoside chloride) were HPLC grade (>95\% purity) and were purchased from Extrasynthese (Lyon, France). Other standards such as 5-O-caffeoylquinic acid (5-CQA), dicaffeoyltartaric acid (DCTA), quercetin 3-O-(6"-malonyl)- $\beta$-D-glucoside (QMG), and kaempferol 3-O-glucoside (KG) were purchased from Sigma-Aldrich (Seoul, Korea).

\section{Plant material}

Lettuce were grown at the research farm of the National Agrobiodiversity Center (NAC), Rural Development Administration (RDA), Jeonju ( $\left.35^{\circ} 49^{\prime} 18^{\prime \prime} \mathrm{N}, 127^{\circ} 08^{\prime} 56^{\prime \prime} \mathrm{E}\right)$, Republic of Korea. Seeds of 22 lettuce cultivars (18 cultivars of RDA breeding lines and four commercial cultivars originated from Korea) obtained from RDA gene bank were sown in plug trays, and seedlings were grown in a greenhouse. Four weeks old seedlings were transplanted to the field of a plastic house with planting density of $20 \times 20 \mathrm{~cm}$. RDA's recommended cultural management practices for lettuce were followed in the field. Each cultivar consisted of 24 plants. Plant growth was maintained using nutrient solution throughout the growing season. Mature lettuce leaf sample, where the head/leaf reaches marketable size, were harvested 75 days after sowing while the bolting stage samples were harvested 120 days 


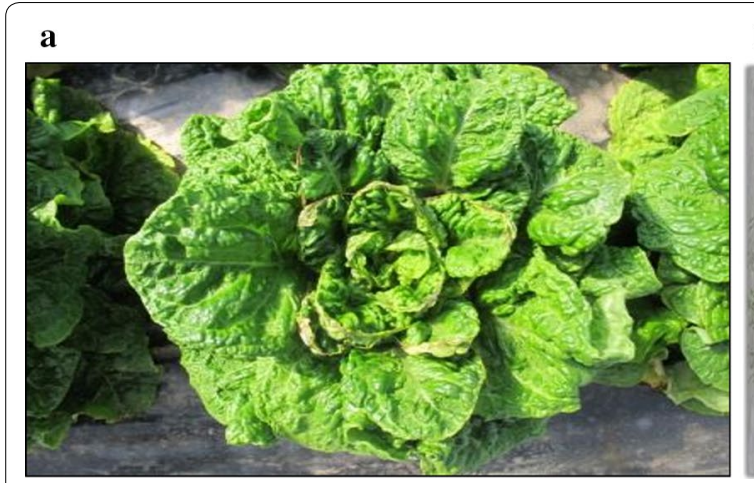

\section{b}

Fig. 1 Representative photos of lettuce at mature stage (a) and bolting stage (b)

after sowing when the elongated stem has produced inflorescences and flowers. These samples were immediately transported to the laboratory. Figure 1 shows a representative photo of lettuce at the mature and bolting stage. The qualitative characters were recorded based on the plant observation on the field and in the laboratory. The experimental design was completely randomized and was conducted in three biological replicates. Lettuce leaf samples were placed in vinyl freezer bags and held at $-80{ }^{\circ} \mathrm{C}$. The frozen samples were subsequently lyophilized for $48 \mathrm{~h}$ using vacuum freeze-drier (Ilshibiobase, Rijssen, Netherlands). Freeze-dried samples were ground to a fine powder using a mortar and pestle, and held at $-80^{\circ} \mathrm{C}$ for the subsequent experiment.

\section{Extraction and analysis of phenolic acids and flavonoids}

The extraction procedure was adopted from Llorach et al. [5] with some modifications. Briefly, $0.25 \mathrm{~g}$ of lyophilized powdered sample was extracted with $10 \mathrm{~mL}$ of methanol/water/formic acid (25:22:3, v:v:v) mixture using a thermostatic shaking water bath (agitation rate $140 \mathrm{rpm}$ ) at a temperature of $40{ }^{\circ} \mathrm{C}$ for $3 \mathrm{~h}$. Then, the extract was centrifuged at $5000 \times g$ for $15 \mathrm{~min}$ at $4{ }^{\circ} \mathrm{C}$ and the supernatant was recovered. The residue was further extracted following the same step described above. The obtained supernatants were combined, filtered through a 0.45 $\mu \mathrm{m}$ polytetrafluoroethylene (PTFE) filter (Millipore Ltd., Bedford, MA, USA), dissolved in an appropriate concentration, and used for subsequent analysis (LC-MS/MS analysis and ABTS assay).

\section{LC-MS/MS analysis}

Analysis of phenolic acids and flavonoids were performed using an ultra-performance liquid chromatography (UPLC) system (Waters, Milford, USA) equipped with autosampler and photodiode array (PDA) detector. The mobile phase compositions were water with
$0.1 \%$ formic acid (A) and acetonitrile with $0.1 \%$ formic acid (B) with a solvent flow rate of $0.4 \mathrm{~mL} / \mathrm{min}$. Sample injection volume was $2 \mu \mathrm{L}$. A gradient elution was followed from 8 to $15 \%$ B for the first $5 \mathrm{~min}$, from 15 to $18 \% \mathrm{~B}$ for the next $5 \mathrm{~min}$, and remaining gradient from 18 to $90 \%$ B for the last $5 \mathrm{~min}$. A post run analysis was held for $5 \mathrm{~min}$. The UV chromatograms were recorded at $330 \mathrm{~nm}$. The metabolites eluted from the column were detected by a high-resolution tandem mass spectrometer SYNAPT G2 Si HDMS QTOF (Waters) in negative ion mode. The capillary voltage and the cone voltage were set at $1 \mathrm{kV}$ and $40 \mathrm{~V}$, respectively. Centroid $M S^{\mathrm{E}}$ mode was used to collect the mass spectrometry data. The primary scan ranged from 50 to $1200 \mathrm{Da}$ and the scanning time was $0.2 \mathrm{~s}$. All the parent ions were fragmented using 20-40 eV. The information on all fragments was collected and the time was $0.2 \mathrm{~s}$. For accurate mass acquisition, leucine-enkephalin $\left([\mathrm{M}-\mathrm{H}]^{-}=554.2615\right)$ at a flow rate of $10 \mu \mathrm{L} / \mathrm{min}$ was used as a lock mass by a lock spray interface. Data acquisition and analysis were controlled by Waters UNIFI V1.71 software. The scan range in MS and MS/MS modes was from 50 to $1200 \mathrm{~m} / \mathrm{z}$.

\section{Extraction, hydrolysis, and analysis of anthocyanidins}

Anthocyanidins extraction and hydrolysis were conducted based on the methodology used in a previous report with some modification [1]. Briefly, $10 \mathrm{mg}$ of finely powdered lyophilized lettuce was mixed with $1.5 \mathrm{~mL}$ of an aqueous methanol solution containing $2 \mathrm{~N} \mathrm{HCL}$ $(50 \mathrm{~mL}$ of methanol $+33 \mathrm{~mL}$ of water $+17 \mathrm{~mL}$ of $37 \%$ $\mathrm{HCL}$ ). The mixture was sonicated for $15 \mathrm{~min}$ in a sonication water bath $(300 \mathrm{w}, 60 \mathrm{~Hz})$ followed by centrifugation (10 min, $4000 \mathrm{rpm}$ ). The supernatant was filtered through a $0.45-\mu \mathrm{m}$ PTFE filter (Millipore Ltd., Bedford, MA, USA) and transferred to a vial with a Teflon-lined screw cap. The vial was placed in a preheated thermostatic water bath and hydrolyzed at $100{ }^{\circ} \mathrm{C}$ for $60 \mathrm{~min}$. The standard of cyanidin 3-O-glucoside chloride was 
hydrolyzed following a similar procedure described above to obtain the cyanidin. Hydrolyzed samples were cooled to room temperature, made up to $5 \mathrm{~mL}$, and immediately analyzed using UPLC.

Agilent 1290 infinity II UPLC (Agilent Technologies, Santa Clara, CA, USA) system equipped with an autosampler and PDA detector was used for analysis of cyanidin while Agilent eclipse plus C18 $(1.8 \mu \mathrm{m}, 2.1 \times 50 \mathrm{~mm})$ column was used for separation. The column thermostat was maintained at $25{ }^{\circ} \mathrm{C}$. The solvent system consisted of $0.1 \%$ formic acid in water (mobile phase A) and $0.1 \%$ formic acid in acetonitrile (mobile phase B). A gradient elution was followed from 8 to $15 \%$ B for the first $5 \mathrm{~min}$, from 15 to $18 \%$ B for the next $5 \mathrm{~min}$, and followed by a 2 min isocratic elution at $18 \%$ of B. A post run analysis was kept for $5 \mathrm{~min}$. The sample injection volume and mobile phase flow rate was kept at $3 \mu \mathrm{L}$ and $0.4 \mathrm{~mL} / \mathrm{min}$, respectively. The signal acquisition wavelength was set at $520 \mathrm{~nm}$. The quantification of cyanidin was done using a calibration equation $\left(Y=12854 X-12.13, R^{2}=0.9996\right.$; where $\mathrm{Y}$ stands for peak area and $\mathrm{X}$ for concentration) which was constructed using a standard of hydrolyzed cyanidin 3-O-glucoside chloride (cyanidin).

\section{Extraction, separation, and analysis of sesquiterpene lactones (SLs)}

Samples were extracted based on the method described in a previous report [20] with some modifications. In brief, powdered lyophilized lettuce $(0.25 \mathrm{~g})$ was mixed to $100 \mathrm{~mL}$ methanol, refluxed at $65^{\circ} \mathrm{C}$ for $1 \frac{1}{3} \mathrm{~h}$, and filtered through a Whatman \#2 filter paper. The solvent was evaporated under reduced pressure using High Capacity Centrifugal Evaporator (Genevac, HT-4X, $5 \mathrm{~mm} \mathrm{Hg}$, $\left.30-35{ }^{\circ} \mathrm{C}\right)$. The crude extract was then re-dissolved with water to a final volume of $20 \mathrm{~mL}$ and partitioned two times with $20 \mathrm{~mL}$ chloroform. The chloroform phase was dried over anhydrous magnesium sulfate and evaporated at reduced temperature and pressure using High Capacity Centrifugal Evaporator (Genevac, HT- $4 \mathrm{X}, 5 \mathrm{~mm} \mathrm{Hg}$, $\left.30-35{ }^{\circ} \mathrm{C}\right)$. The residue was re-dissolved in $0.4 \mathrm{~mL}$ of methanol/chloroform (1/2, v/v) AND the SLs separated using high-performance liquid chromatography (HPLC).

The analysis of SLs was performed using an Agilent 1260 infinity HPLC system (Agilent Technologies, Santa Clara, CA, USA) equipped with a degasser, autosampler, and PDA detector (SPD-M10A). A Phenomenex Luna C18 $(5 \mu \mathrm{m}, 250 \times 4.6 \mathrm{~mm})$ column, maintained at $30^{\circ} \mathrm{C}$, was used for separation of the SLs. The solvent system was comprised of water (mobile phase $\mathrm{A}$ ) and acetonitrile (mobile phase $\mathrm{B}$ ). The elution program was as follows: 0-3 min, 10\% B; 5-15 min, 35\% B; 15-25 min, 35-100\% $\mathrm{B}$, and $25-30 \mathrm{~min}, 100 \% \mathrm{~B}$. The SLs were monitored at a wavelength of $256 \mathrm{~nm}$. The flow rate and injection volume were kept at $0.8 \mathrm{~mL} / \mathrm{min}$ and $20 \mu \mathrm{L}$, respectively. Quantification was done using calibration equations (lactucin, $\mathrm{Y}=3938.6 \mathrm{X}-4.7184 \mathrm{R}^{2}=1$; lactucopicirin, $Y=2606.8 X+1.2828, R^{2}=1$; where $Y$ stands for peak area and $\mathrm{X}$ for concentration) derived from the calibration curves of the corresponding standards.

\section{ABTS assay}

2,2'-Azinobis-(3-ethylbenzothiazoline-6-sulfonic acid) (ABTS) radical scavenging activity was estimated using an improved ABTS decolorization assay described by Re et al. [21] with little modifications. In brief, an ABTS radical cation was generated by reacting $7 \mathrm{mM}$ ABTS stock solution which was prepared using water with $2.45 \mathrm{mM}$ potassium persulphate (final concentration) followed by an overnight incubation of the mixture in the dark at room temperature. The ABTS radical cation solution was further diluted with water to obtain an absorbance of $0.7 \pm 0.02$ at $734 \mathrm{~nm}$. A test solution was prepared by mixing diluted ABTS radical cation solution $(190 \mu \mathrm{L})$ with $10 \mu \mathrm{L}$ of sample solution or standard. After $6 \mathrm{~min}$, absorbance at $734 \mathrm{~nm}$ was determined using an Eon Microplate Spectrophotometer (Bio-Tek, Winooski, VT, USA). The potential of lettuce extract to scavenge ABTS radical was calculated using the following equation:

$$
\begin{aligned}
\text { ABTS scavenging activity }= & 1-\left(\mathrm{A}_{\text {sample }}-\mathrm{A}_{\text {sample blank }}\right) / \\
& \left(\mathrm{A}_{\text {control }}-\mathrm{A}_{\text {control blank }}\right)
\end{aligned}
$$

$\mathrm{A}_{\text {sample }}$ is absorbance of test solution; $\mathrm{A}_{\text {sample blank }}$ is the absorbance of solvents used in the test solution; $\mathrm{A}_{\text {control }}$ is the absorbance of ABTS radical cation solution; and water is used as $\mathrm{A}_{\text {control blank. The radical scavenging activ- }}$ ity was reported as mg TROLOX equivalent per gram (mg TE/g) DW obtained by comparing the results with a TROLOX calibration curve. The calibration equation used for quantification was $\mathrm{Y}=6.4879 \mathrm{X}+0.0024$ (where $\mathrm{Y}$ stands for absorbance and $\mathrm{X}$ for concentration; $\left.\mathrm{R}^{2}=0.9983\right)$.

\section{Statistical analysis}

Results were expressed as mean \pm standard deviation (SD) of biological triplicates (each replicate tested three times) based on the dry weight (DW) of the lyophilized sample. The data were analyzed using a one-way ANOVA with SPSS 17.0 software followed by Duncan's multiple range test using SPSS V. 17.0 statistical program (SPSS Inc., Chicago, USA). Significant level was set at $\mathrm{p}<0.05$. The correlation between ABTS radical scavenging activity and cyanidin content of lettuce was determined by two-tailed Pearson correlation analysis $(p<0.01)$ with the same program. The multivariate analysis was performed 
using PAST (Palaeontological statistics, version 3.06) [22] to create a principal component analysis (PCA) score and loading plots.

\section{Results and discussion}

Differently pigmented (green, green/red, and red) lettuce plants belonging to four different growth types including, crisphead, butterhead, cos (romaine), and leafy, harvested at the mature and bolting stages, were evaluated for their metabolites compositions and antioxidant potential. The extraction and analysis of phenolics and flavonoids, cyanidin, and sesquiterpene lactones were conducted using separate procedures to ensure a maximum throughput of each group of compounds. Samples were lyophilized before extraction because freeze drying allows highest recovery of polyphenols in previous studies [23].

\section{Identification of phenolic acids and flavonoids in lettuce cultivars}

The identification and characterization of phenolic acids and flavonoids for which standards were available were performed by comparison to their UV/Vis spectra, retention times, and the MS and MS/MS fragmentation patterns of the ions recorded in negative ion mode. The other compounds were elucidated based on the available data on literature, the UV/Vis spectrum when it was available to assign a phenolic class and the deprotonated dimer ion $[2 \mathrm{M}-\mathrm{H}]^{-}$. The identities, retention times, UV absorption maxima's, and observed molecular and fragment ions of the identified compounds from lettuce cultivars by UPLC-PDA-Q-TOF-HDMS are presented in Table 1. Reversed-phase liquid chromatography using gradient acidic water and acetonitrile mobile phase conditions have been employed for separation of phenolic compounds in lettuce samples in earlier reports [8]. The chromatographic conditions allowed a baseline separation of the peaks of the phenolic compounds in $15 \mathrm{~min}$. A representative chromatogram of the identified compounds is presented in Fig. 2. Three peaks (1, 2, and 3) presented almost similar UV spectra and gave the same [M-H] $]^{-}$ion at $m / z 353$, fragment ion at $m / z 191$ ([quinic acid- $\left.\mathrm{H}]^{-}\right)$, and deprotonated dimer ion $\left([2 \mathrm{M}-\mathrm{H}]^{-}\right)$at $m / z$ 707. Those peaks were identified as monocaffeoylquinic acids. MS/MS spectra did not show fragment ion at $\mathrm{m} / \mathrm{z} 173$ ([quinic acid $\left.-\mathrm{H}-\mathrm{H}_{2} \mathrm{O}\right]^{-}$), characteristically formed in the negative ion mode when the cinnamoyl group is bonded to the quinic moiety at position 4 of caffeoylquinic acid structure [24], confirming the absence of 4-O-caffeoylquinic acid. Peak 3 was unambiguously identified as 5-O-caffeoylquinic acid (5-CQA) by comparison to its UV/Vis spectra, retention time, and the patterns of MS and MS/MS fragmentations of the standard. Thus, peaks $\mathbf{1}$ and $\mathbf{2}$ were respectively identified as
1-O-caffeoylquinic acid (1-CQA) and 3-O-caffeoylquinic acid (3-CQA) based on their MS parent ion, deprotonated dimer ion, MS/MS product ions, and by comparing with the elution order of caffeoylquinic acids in earlier reports [25, 26]. 1-CQA, 3-CQA, and 5-CQA have been already reported in lettuce [24]. Peak 4 presented MS parent ion at $m / z 367$ and fragment ions at $\mathrm{m} / \mathrm{z} 191$ [quinic acid] ${ }^{-}, 173$ [quinic acid $\left.-\mathrm{H}_{2} \mathrm{O}-\mathrm{H}^{+}\right]^{-}, 149$ [ferulic acid ion $-\mathrm{COO}]^{-}$, and $134\left[\text { ferulic acid ion-COO- } \mathrm{CH}_{3}\right]^{-}$. The MS/MS base peak at $\mathrm{m} / \mathrm{z} 191$ indicate a C-5 substituent [27]. Hence, this peak was assigned as 5 -feruloylquinic acid (5-FQA) by comparison to the fragmentation behavior and UV spectra of previous reports [28-30]. The presence of 5-FQA has also been previously reported in green lettuce [31]. Peak 5, which presented MS parent ion at $\mathrm{m} / \mathrm{z} 473$, was identified as dicaffeoyltartaric acid (DCTA) on the basis of its concordance with retention time, UV/Vis spectra, MS, and $M S^{2}$ fragmentation pattern of the authentic standard. Similar to previous studies [5, 17, 24], DCTA was found to be the most abundant phenolic acid in lettuce. Peaks 6, 9, and 10 were identified as kaempferol derivatives namely kaempferol glucuronide (KGR), kaempferol malonylglucoside (KMG), and methylkaempferol glucuronide (MKGR), respectively, on the basis of UV/Vis and mass spectral data of the previous reports $[5,11,24,32]$. The $[\mathrm{M}-\mathrm{H}]^{-}$at $m / z 461$ and $\left[\mathrm{Y}_{\mathrm{o}}\right]^{-}$at $\mathrm{m} / \mathrm{z} 285$ of peak 6 were characteristic properties of KGR. Though luteolin and kaempferol aglycone are isobaric, their derivatives can be distinguished based on $\mathrm{MS}^{\mathrm{n}}$ data [24]. Peak 6 yielded the base peak at $\mathrm{m} / \mathrm{z}$ $285\left([\mathrm{Yo}]^{-}\right)$at the high energy function indicating it is kaempferol derivative. In the low energy function, peak 9 presented $[\mathrm{M}-\mathrm{H}]^{-}$at $m / z 533$ and a base peak at $m / z$ 489 due to loss of $\mathrm{CO}_{2}$. The high energy function yielded a base peak at $m / z 285\left(\left[\mathrm{Yo}^{-}\right]^{-}\right.$, suggesting that this compound is a kaempferol derivative. Based on the UV/Vis and mass spectral information, peak 9 was identified as KMG. Glucosides, glucuronides, and malonylglucosides of kaempferol were already detected in lettuce $[5,11,24$, 32]. Peak 10 presented $[\mathrm{M}-\mathrm{H}]^{-}$at $\mathrm{m} / \mathrm{z} 475$ as a base peak and a dimer ion at $m / z 951$. The MS/MS yielded fragment ions at $\mathrm{m} / \mathrm{z} 299,285$, and 284 which could be due to the loss of glucuronide moiety from the parent ion, kaempferol aglycone, and loss of the methyl group from the ion at $\mathrm{m} / \mathrm{z} 299$, respectively. Hence, this peak was tentatively identified as methylkaempferol glucuronide. The methyl conjugate of kaempferol glucuronide could result from methylation with methanol during the methanol/water/ formic acid mixture extraction process as observed in the previous report [33]. Peak 7 was unambiguously identified as quercetin malonylglucoside (QMG) by comparison to the retention time, UV/vis and mass spectra of the authentic standard. It presented $[\mathrm{M}-\mathrm{H}]^{-}$at $m / z 549$, 
Table 1 Retention times, ultraviolet-visible absorption maxima, and mass spectral data of phenolic acids and flavonoids in leaves of lettuce cultivars

\begin{tabular}{|c|c|c|c|c|c|c|c|}
\hline Peak no & $t_{R}(\min )$ & $U V \lambda_{\max }(n m)$ & Neutral mass (Da) & Observed $\mathrm{m} / \mathrm{z}[\mathrm{M}-\mathrm{H}]$ & $\begin{array}{l}\text { Dimer and fragment } \\
\text { ions in ESI/MS/MS }\end{array}$ & Mass error, $\mathrm{ppm}$ & Identification \\
\hline 1 & 1.32 & 300sh, 326 & 354.0951 & 353.08698 & $\begin{array}{l}\text { 707.18302 [2M-H] } \\
\text { 191.05512 }{\text { [Quin- }]^{-}}^{-} \\
85.02891\end{array}$ & -2.3 & $\begin{array}{l}\text { 1-O-Caffeoylquinic acid } \\
\text { (1-CQA) }\end{array}$ \\
\hline 2 & 1.54 & 300sh, 324 & 354.0951 & 353.08674 & $\begin{array}{l}\text { 707.18124 [2M-H] }]^{-} \\
\text {191.05503 [Quin-H] } \\
179.03365\end{array}$ & -3.0 & $\begin{array}{l}\text { 3-O-Caffeoylquinic acid } \\
\text { (3-CQA) }\end{array}$ \\
\hline 3 & 2.39 & 300sh, 324 & 354.0951 & 353.08697 & $\begin{array}{l}\text { 707.18302[2M-H] }]^{-} \\
\left.\text {191.05512[Quin- }{ }^{-}\right]^{-} \\
85.02891\end{array}$ & -2.4 & $\begin{array}{l}\text { 5-O-Caffeoylquinic acid } \\
\text { (5-CQA) }\end{array}$ \\
\hline 4 & 4.64 & 328 & 368.1107 & 367.1025 & $191.05493,134.03524$ & -2.6 & $\begin{array}{l}\text { 5-Feruloylquinic acid } \\
\text { (5-FQA) }\end{array}$ \\
\hline 5 & 6.62 & 301sh, 324 & 474.0798 & 473.0719 & $\begin{array}{l}947.15066[2 \mathrm{M}-\mathrm{H}]- \\
311.03986[\mathrm{Caftar}- \\
\mathrm{H}^{-}, 293.02929 \\
{\left[\mathrm{Caftar}-\mathrm{H}-\mathrm{H}_{2} \mathrm{O}\right]^{-}} \\
179.03366[\mathrm{Caffeic}- \\
\mathrm{H}^{-}, 149.00859[\text { Tar- } \\
\text { taric-H] }]^{-} 133.02836, \\
112.98729\end{array}$ & -1.4 & $\begin{array}{l}\text { Dicaffeoyltartaric acid } \\
\text { (DCTA) }\end{array}$ \\
\hline 6 & 7.36 & 328 & 462.0798 & 461.07175 & $285.03951,133.02837$ & -1.7 & $\begin{array}{l}\text { Kaempferol glucuronide } \\
\text { (KGR) }\end{array}$ \\
\hline 7 & 7.79 & 252,360 & 550.09587 & 549.08832 & $\begin{array}{l}1099.18568[2 \mathrm{M}-\mathrm{H}]^{-}, \\
505.09879[\mathrm{M}-\mathrm{H}- \\
\left.\mathrm{CO}_{2}\right], 300.02672 \\
{\left[\mathrm{Y}_{0}-\mathrm{H}\right], 271.02369,} \\
255.02863 \\
{\left[\mathrm{Y}_{0}-\mathrm{CHO}-\mathrm{OH}\right]^{-}}\end{array}$ & -0.5 & $\begin{array}{l}\text { Quercetin malonylgluco- } \\
\text { side (QMG) }\end{array}$ \\
\hline 8 & 8.66 & 330 & 516.1268 & 515.1190 & $\begin{array}{l}1031.24625 \text { [2M-H], } \\
353.08678[\text { Cafquin- } \\
\text { H], } 191.05486 \\
\text { [Quin-H]-, } 179.03376 \\
\text { [Caffeic-H]-, } 135.4416 \\
\text { [Caffeic-H-CO }{ }_{2} \text { ] }\end{array}$ & -1.0 & $\begin{array}{l}\text { Dicaffeoylquinic acid } \\
\text { (DCQA) }\end{array}$ \\
\hline 9 & 8.88 & 348 & 534.1009 & 533.09327 & $\begin{array}{l}\text { 489.10292, 285.03897 } \\
\text { [luteolin- } \\
\text { H]-284.03133, } \\
133.02831\end{array}$ & -0.7 & $\begin{array}{l}\text { Kaempferol malonylglu- } \\
\text { coside (KMG) }\end{array}$ \\
\hline 10 & 9.53 & 328 & 476.0955 & 475.08749 & $\begin{array}{l}951.18882[2 \mathrm{M}- \\
\mathrm{H}], 299.05492 \\
285.03121,284.03121\end{array}$ & -1.5 & $\begin{array}{l}\text { Methylkaempferol glu- } \\
\text { curonide (MKGR) }\end{array}$ \\
\hline
\end{tabular}

$\left[\mathrm{Y}_{\mathrm{o}}-\mathrm{H}\right]^{-}$at 300 , and $\left[\mathrm{M}-\mathrm{H}-\mathrm{CO}_{2}\right]^{-}$(base peak) at $\mathrm{m} / \mathrm{z} 505$, which are the characteristic properties of QMG. As it was previously pointed out by Abu-reidah et al. [34], the loss of $\mathrm{CO}_{2}$ was a common feature of compounds presenting the malonyl group due to in-source fragmentation. This caused the $[\mathrm{M}-\mathrm{H}]^{-}$to appear in lower abundance in the mass spectra than the product ion $\left[\mathrm{M}-\mathrm{H}-\mathrm{CO}_{2}\right]^{-}$as observed for peaks 7 and 9. The identification of QMG which has been previously detected in lettuce $[5,7,34$, $35]$, was further confirmed by the presence of $[2 \mathrm{M}-\mathrm{H}]^{-}$ ion at $m / z$ 1099. Peak 8 which presented $[\mathrm{M}-\mathrm{H}]^{-}$at $\mathrm{m} / \mathrm{z}$ 515 , was identified as dicaffeoylquinic acid (DCQA). The first MS/MS fragment of DCQA was due to the loss of one of the caffeoyl moieties leading to the precursor ion of caffeoyl quinic acid (at $m / z$ 353). The subsequent fragmentations presented similar ions as described above for peaks 1, 2 and 3. The identification of DCQA, also reported in lettuce $[5,7,24,34]$, was further supported by the presence of dimer ion at $m / z 1031$.

\section{Quantitative variations of metabolites and antioxidant activity among 22 cultivars at mature and bolting stages} To investigate the quantitative variability of metabolites in lettuce cultivars, representative leaf samples were prepared for each cultivar at the mature and bolting stages. Table 2 shows the phenolic acid and flavonoid contents of 


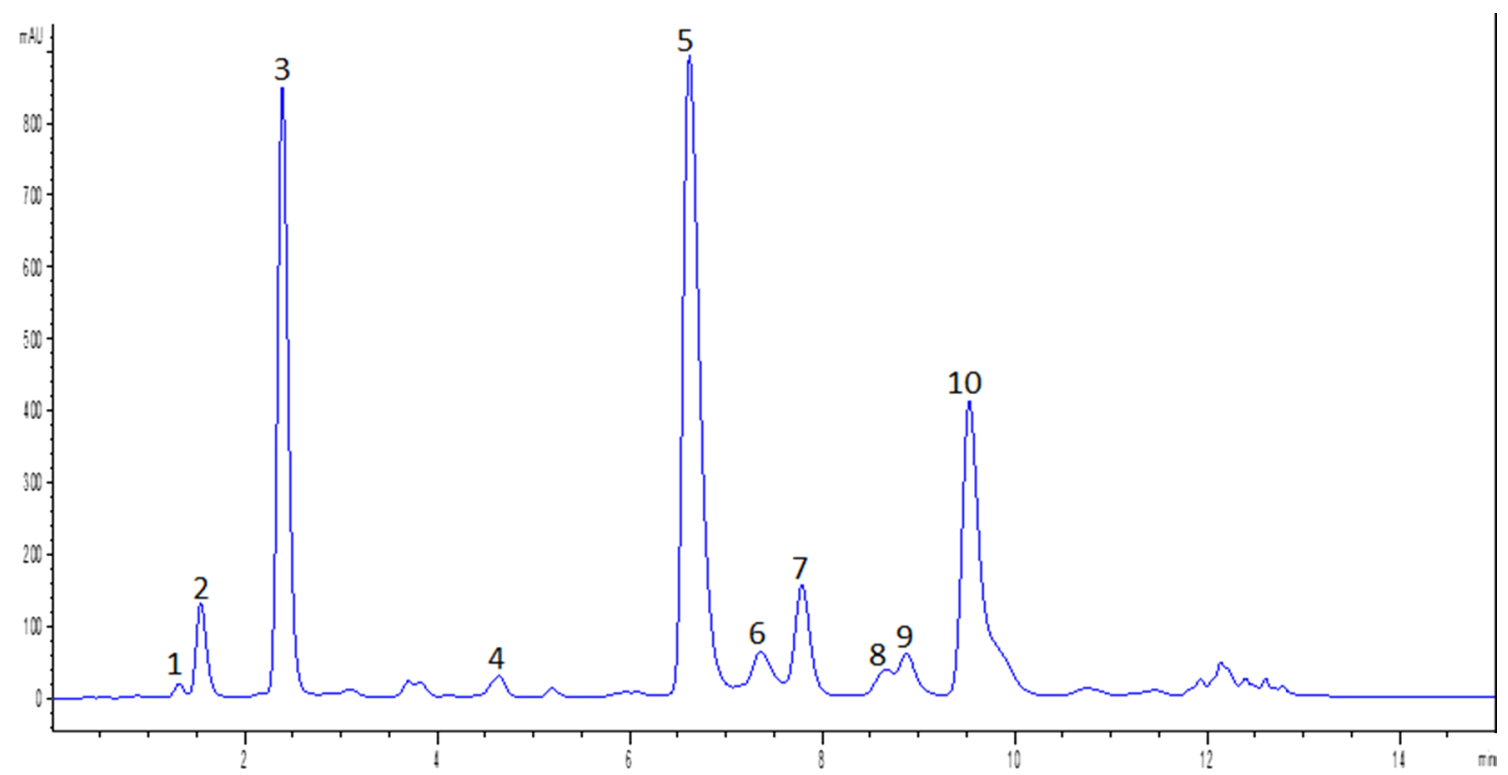

Fig. 2 Representative chromatogram of identified compounds in lettuce cultivars. The peak numbers correspond to the identified compounds as presented in Table 1

22 lettuce cultivars expressed as $\mathrm{mg} / 100 \mathrm{~g}$ of dry weight (DW). Calibration curves were created using authentic standards (5-CQA, DCTA, KG, and QMG) for calculations of results. Among the ten compounds identified using UPLC-PDA-Q-TOF-HDMS, eight of them showing prominent peaks were quantified. For quantification of compounds with no standards available, the most similar compounds were used taking into account the nature of the compounds and their molecular weight. Hence, 3-CQA and 5-FQA were quantified using a calibration curve of 5-CQA whereas kaempferol derivatives were quantified using KG. To investigate the relationship between leaf age and phenolic compositions of lettuce, the individual phenolic acids and flavonoids in lettuce at mature (marketable stage) and bolting stages were quantified. The main phenolic acid components of lettuce in this study were quinic and tartaric acid derivatives where 5-CQA and DCTA contributed 20 to $74 \%$ and 15 to $56 \%$ of the total content of the sum of phenolic acids determined, respectively. The maximum and minimum content of phenolic acids (sum of individual phenolic acids quantified) in lettuce at the mature stage was found in a green pigmented cultivars "Chunpungjeokchukmyeon" (54.6 mg/100 g DW) and "Adam" (18.3 mg/100 g DW), respectively. At the bolting stage, red pigmented commercial cultivar, "Tomalin", had the highest amount of phenolic acid (54.6 mg/100 g DW) while green pigmented "Pungseong" cultivar contained the least amount (15.5 mg/100 g DW). Kaempferol derivatives were the major flavonoids detected in lettuce samples. There is also a significant content of QMG measured in lettuce especially at the bolting stage. The sum of flavonoids quantified in this study ranged from 9.2 to $25.9 \mathrm{mg} / 100 \mathrm{~g}$ DW and 14.9 to $83.0 \mathrm{mg} / 100 \mathrm{~g}$ DW in mature and bolting stage lettuce samples, respectively. We have noticed that 3-CQA, KMG, and MKGR were higher (up to 300\%) at the bolting than the mature stage for most of the samples. Lettuce leaves at the bolting stage exhibited significantly higher (up to 12.5-fold) QMG than at the mature stage. Unlike other cultivars, "Cheonsang", a green colored romaine lettuce, showed two times less QMG at the mature stage compared to the bolting stage. However, at least $70 \%$ of the samples showed up to 4.5-, 3.2-, and 3.0-times higher content of 5-CQA, 5-FQA, and KGR at the mature stage compared to bolting stage leaves, respectively. In several samples, 1-CQA and DCQA were below the level of the limit of quantification, thus the quantitative information is not included in this report. In this study, the most commonly found phenolic acids are represented by chlorogenic acids and chicoric acids while the flavonoids constitute glucuronide and glucoside conjugates of quercetin and kaempferol which was in agreement with previous reports $[6,17,24]$.

Anthocyanins are responsible for the red pigments in lettuce [1, 4]. Anthocyanins exhibit specific UV/ Vis absorption maxima at about $520 \mathrm{~nm}$. The identification of anthocyanidins (an acid hydrolyzed form of anthocyanin) was conducted by comparing the retention time and UV/Vis spectra of acid hydrolyzed cyanidin 3-O-glucoside chloride standard. The anthocyanins 


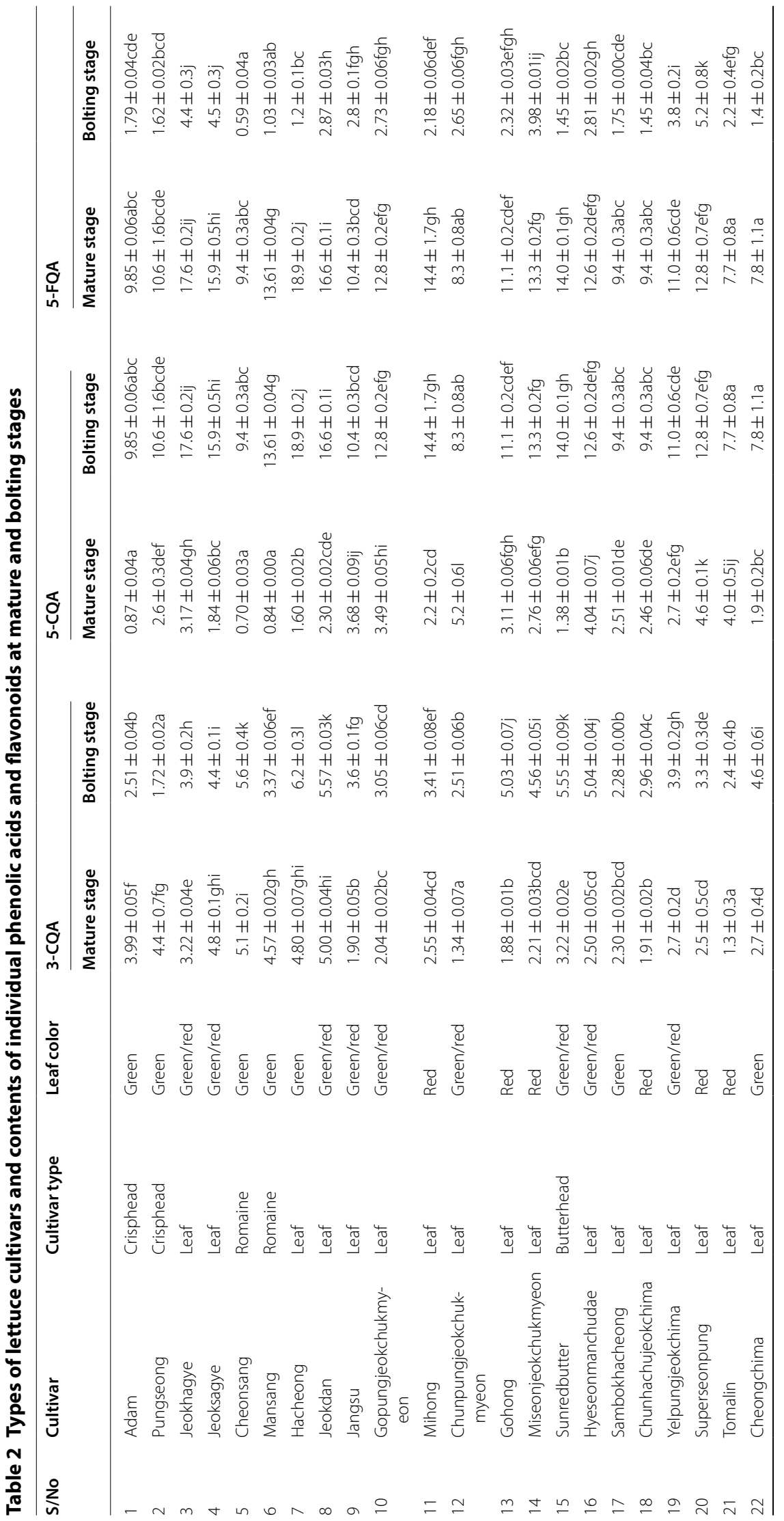




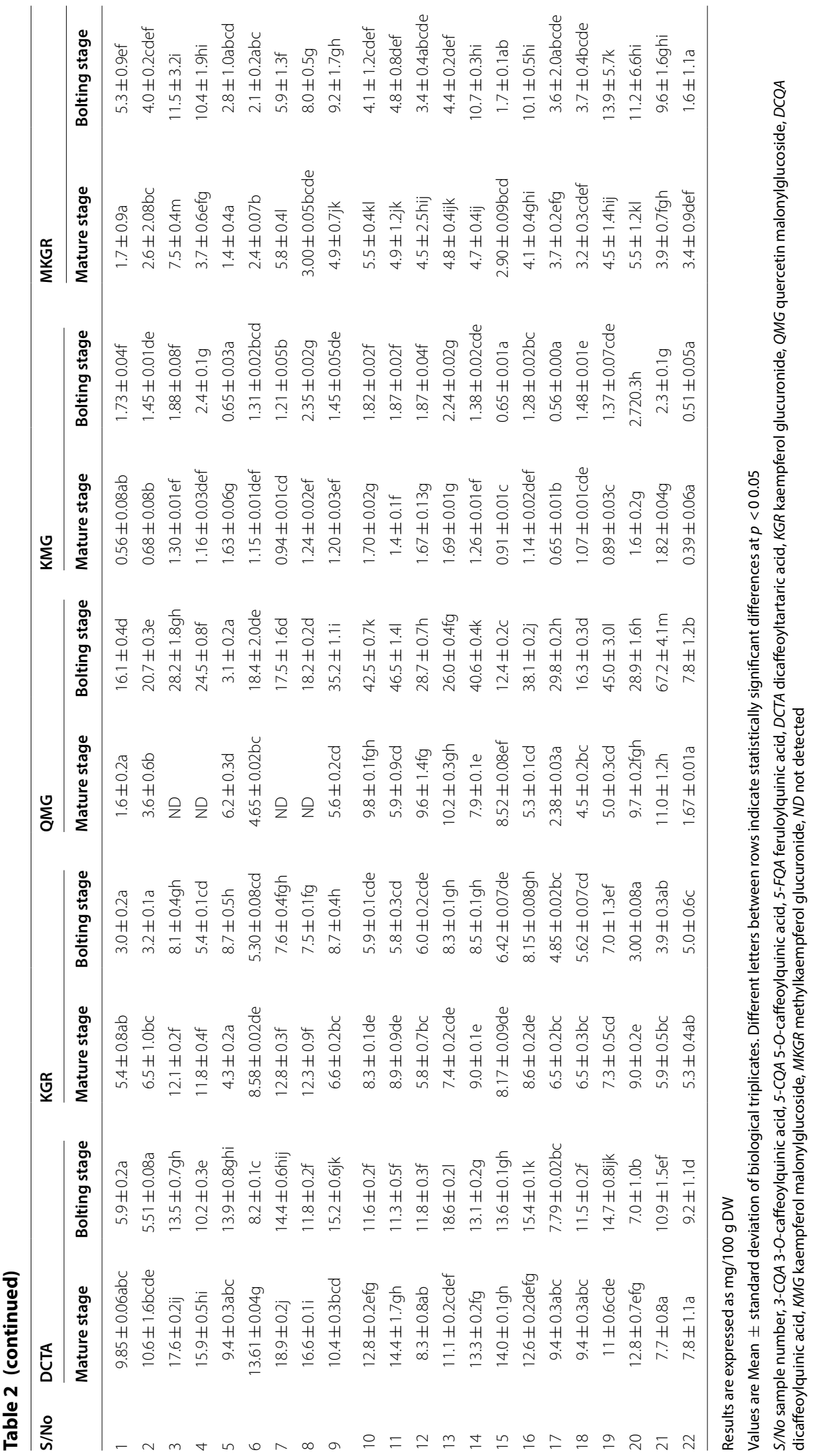


were quantified after acid hydrolysis, which could convert these pigments into aglycone form. Cyanidin was the single major anthocyanidin detected in this study. The content of cyanidin in red and green/red pigmented lettuce cultivars is presented in Fig. 3. However, cyanidin was not detected in green pigmented lettuce cultivars. The cyanidin content was ranged from 0.3 ("Sunredbutter") to $9.7 \mathrm{mg} / \mathrm{g}$ DW ("Tomalin") in mature stage lettuce and 0.5 ("Superseonpung") to $10.2 \mathrm{mg} / \mathrm{g} \mathrm{DW}$ ("Jangsu") in bolting stage lettuce. A statistically significant difference $(p<0.05)$ in cyanidin content was observed among red and green/red cultivars of lettuce. The cyanidin content in some of the cultivars of this study is quite higher than an earlier report by Kim et al. [1], which recorded 0.08 to $3.66 \mathrm{mg} / \mathrm{g} \mathrm{DW}$ in baby-sized green/red and red lettuce leaves. Llorach et al. [5] found anthocyanin level of 0.259 and $0.456 \mathrm{mg} / \mathrm{g}$ (fresh weight basis) in "red oak leaf" and "lollo rosso" samples, respectively. In contrast, Pérez-López et al. [6], recorded quite higher cyanidin content (higher than $30 \mathrm{mg} / \mathrm{g}$ DW) in red pigmented lettuce cultivar. There was also a significant difference in cyanidin content between lettuce at the mature and bolting stages in some of the cultivars. An increase in cyanidin content was recorded at the bolting stage for some of lettuce cultivars (greater than 100\% for "Gohong", "Sunredbutter", and "Yelpungjeokchima" and 43 to $63 \%$ for "Jangsu", "Jeokdan", and "Jeokhagye") while a decrease by $81 \%$ was exhibited in "Supersongpung". For the other cultivars, the increase/decrease in cyanidin content at the reproductive stage was not more than $20 \%$. It has been previously reported that the cyanidin level of lettuce is influenced by the red color intensity, genotype, temperature, and growing conditions $[4,14,36]$. The amount of cyanidin accumulation is related to the degree of leaf redness, suggesting the visual assessment of the redness intensity could help as a measure of the relative quantity of cyanidin in lettuce. As reported earlier [12, 37], cyanindin 3-malonylglucoside is the principal anthocyanin in red pigmented lettuce. In addition to providing sensorial characteristics of food products [38], cyanidin 3-malonylglucoside in red lettuce has been shown to possess several health properties such as mitigating photoinhibitory and photooxidative damage [39].

SLs are C-15 terpenoids that naturally occur in the form of hydrocarbons, alcohols, ketones, aldehydes, acids or lactones [40]. Lactucin and lactucopicrin, the major SLs reported in lettuce, contribute significantly to the bitterness nature of lettuce cultivars [3, 20]. Two bitter sesquiterpene lactones (SLs), lactucin and lactucopicrin, were identified and quantified using HPLC by comparing their retention time and UV/Vis spectra to their corresponding authentic standards. Table 3 presents the mean SLs concentrations, expressed in microgram per gram of dry weight $(\mu \mathrm{g} / \mathrm{g} \mathrm{DW})$, of 22 cultivars cultivated at mature and bolting stages. Analysis of variance (ANOVA) indicated that individual SLs, as well as total SLs concentration, showed significant inter-cultivar variations. The concentration of total SLs (sum of lactucin and lactucopicrin) ranged from 11.7 ("Superseonpung") to 386.7 ("Sunredbutter") $\mu \mathrm{g} / \mathrm{g} \mathrm{DW}$ and 213.0 ("Cheonsang") to 4101.2 ("Superseonpung") $\mu \mathrm{g} / \mathrm{g} \mathrm{DW}$ at the mature and bolting stage, respectively. Since all accessions were grown under similar agronomic conditions, the variations are likely to be genetically controlled. Analysis of SLs including, 8-deoxylactucin, jacquinelin, crepidiaside B and lactuside showed mixed result among 23 accessions of Lactuca aculeata Boiss. grown under standardized glasshouse conditions, suggesting that the genetic factor plays a major role [41]. Another study also showed that the concentration of lactucin (2.9 to $17.2 \mu \mathrm{g} / \mathrm{g} \mathrm{DW})$ and lactucopicrin (8.8 to $36.1 \mu \mathrm{g} / \mathrm{g}$ DW) varied significantly among cultivars due to leaf color and morphology [3]. The content of SLs was

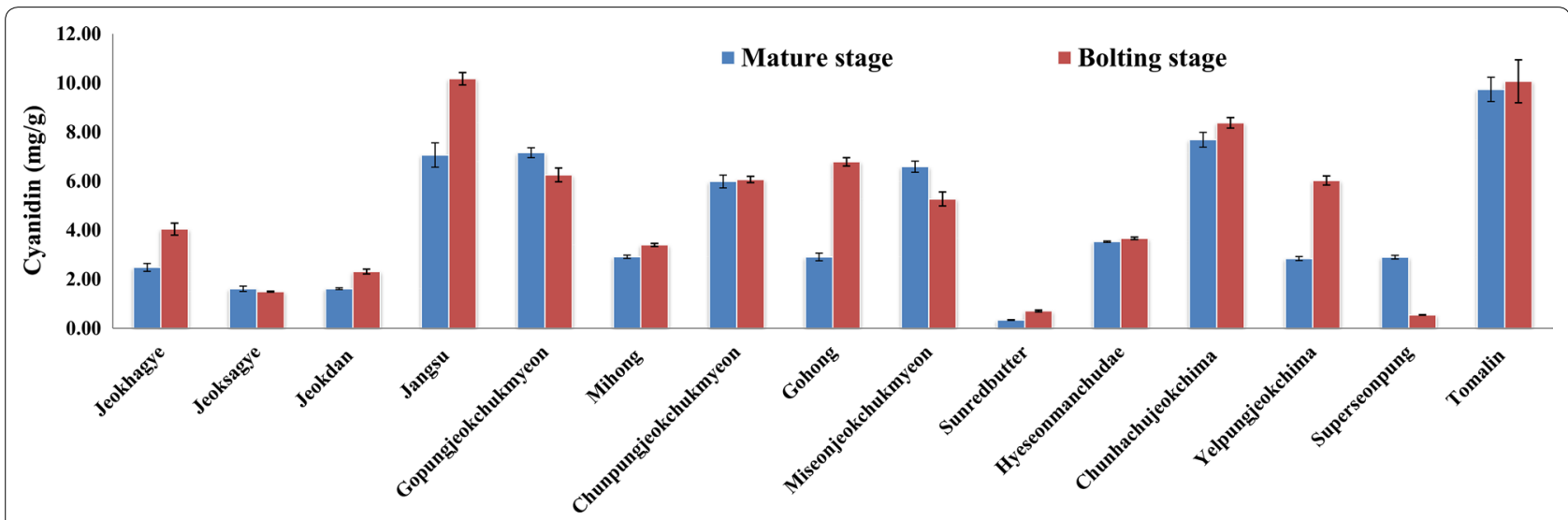

Fig. 3 The content of cyanidin in red and green/red pigmented lettuce cultivars 
Table 3 Concentration of sesquiterpene lactones (SLs) in 22 cultivars of lettuce at mature and bolting stages

\begin{tabular}{|c|c|c|c|c|c|c|c|}
\hline \multirow[t]{2}{*}{ S/No } & \multirow[t]{2}{*}{ Cultivar } & \multicolumn{2}{|l|}{ Lactucin $(\mu \mathrm{g} / \mathrm{g})$} & \multicolumn{2}{|c|}{ Lactucopicrin $(\mu \mathrm{g} / \mathrm{g})$} & \multicolumn{2}{|l|}{ Total SLs $(\mu \mathrm{g} / \mathrm{g})$} \\
\hline & & Mature stage & Bolting stage & Mature stage & Bolting stage & Mature stage & Bolting stage \\
\hline 1 & Adam & $5.2 \pm 0.4 \mathrm{efgh}$ & $174.8 \pm 14.7 b$ & $29.4 \pm 1.71$ & $615.1 \pm 30.2 \mathrm{gh}$ & $34.6 \pm 1.71$ & $789.9 \pm 36.5 \mathrm{ef}$ \\
\hline 2 & Pungseong & $2.2 \pm 0.1 \mathrm{kl}$ & $181.2 \pm 3.0 \mathrm{~b}$ & $29.3 \pm 2.71$ & $1255.8 \pm 12.3 \mathrm{~cd}$ & $31.5 \pm 2.11$ & $1437.1 \pm 11.3 \mathrm{bc}$ \\
\hline 3 & Jeokhagye & $5.3 \pm 0.2 \mathrm{efg}$ & $99.8 \pm 6.8 d$ & $80.4 \pm 1.8 d$ & $1156.9 \pm 64.5$ de & $85.8 \pm 1.5 \mathrm{e}$ & $1256.7 \pm 57.7 \mathrm{bcd}$ \\
\hline 4 & Jeoksagye & $6.6 \pm 0.4 e$ & $81.7 \pm 3.3 \mathrm{ef}$ & $64.7 \pm 3.1 \mathrm{fg}$ & $1396.7 \pm 29.0 b c$ & $71.3 \pm 2.6 \mathrm{fgh}$ & $1478.4 \pm 24.8 \mathrm{bc}$ \\
\hline 5 & Cheonsang & $13.7 \pm 0.2 c$ & $43.8 \pm 2.2 \mathrm{~g}$ & $52.2 \pm 3.7 \mathrm{hijk}$ & $169.2 \pm 9.9 i$ & $65.9 \pm 3.2 \mathrm{hi}$ & $213.0 \pm 9.8 \mathrm{~h}$ \\
\hline 6 & Mansang & $14.9 \pm 1.4 \mathrm{c}$ & $80.4 \pm 2.6 \mathrm{ef}$ & $61.8 \pm 3.8 f g$ & $207.8 \pm 9.1 i$ & $76.7 \pm 4.0$ efg & $288.2 \pm 9.5 \mathrm{gh}$ \\
\hline 7 & Hacheong & $6.1 \pm 0.3 \mathrm{ef}$ & $35.8 \pm 1.8 \mathrm{ghi}$ & $99.0 \pm 6.5 c$ & $1176.4 \pm 112.6 \mathrm{de}$ & $105.1 \pm 5.4 d$ & $1212.2 \pm 93.2 \mathrm{~cd}$ \\
\hline 8 & Jeokdan & $9.8 \pm 0.9 d$ & $84.9 \pm 6.4 \mathrm{def}$ & $124.1 \pm 3.3 b$ & $1227.9 \pm 81.6 \mathrm{~cd}$ & $133.9 \pm 3.4 \mathrm{c}$ & $1312.8 \pm 70.7 \mathrm{bcd}$ \\
\hline 9 & Jangsu & $3.2 \pm 0.3 \mathrm{ijk} \mid$ & $42.3 \pm 1.4 \mathrm{gh}$ & $45.9 \pm 2.1 \mathrm{k}$ & $593 \pm 23.8 \mathrm{gh}$ & $49.1 \pm 1.8 \mathrm{k}$ & $635.2 \pm 20.6 f$ \\
\hline 10 & Gopungjeokchukmyeon & $2.7 \pm 0.2 \mathrm{jkl}$ & $9.7 \pm 0.6 j$ & $60.6 \pm 2.8 f g h i$ & $815.3 \pm 18.6 \mathrm{fg}$ & $63.4 \pm 2.4 \mathrm{hij}$ & $825.1 \pm 15.7 \mathrm{ef}$ \\
\hline 11 & Mihong & $2.2 \pm 0.1 \mathrm{kl}$ & $11.1 \pm 0.8 j$ & $62.5 \pm 2.5 f g$ & $579.2 \pm 31.4 h$ & $64.7 \pm 2.1 \mathrm{hi}$ & $590.3 \pm 26.3 f$ \\
\hline 12 & Chunpungjeokchukmyeon & $2.2 \pm 0.2 \mathrm{kl}$ & $18.0 \pm 0.6 \mathrm{ij}$ & $61.4 \pm 4.4 f g h$ & $628.2 \pm 55.9 \mathrm{gh}$ & $63.6 \pm 3.7 h i j$ & $646.2 \pm 46.0 f$ \\
\hline 13 & Gohong & $3.6 \pm 0.2 \mathrm{hijk}$ & $17.8 \pm 0.6 \mathrm{ij}$ & $64.7 \pm 6.9 f g$ & $662.6 \pm 57.9 \mathrm{gh}$ & $68.3 \pm 5.8 \mathrm{gh}$ & $680.4 \pm 47.3 f$ \\
\hline 14 & Miseonjeokchukmyeon & $4.9 \pm 0.1 \mathrm{fgh}$ & $25.2 \pm 1.6 \mathrm{hij}$ & $74.8 \pm 1.8 \mathrm{de}$ & $1536.9 \pm 132.6 b$ & $79.7 \pm 1.4 \mathrm{ef}$ & $1562.2 \pm 109.1 b$ \\
\hline 15 & Sunredbutter & $41.9 \pm 1.9 a$ & $73.5 \pm 6.5 \mathrm{ef}$ & $344.8 \pm 14.5 a$ & $594.1 \pm 24.8 \mathrm{gh}$ & $386.7 \pm 10.4 a$ & $667.6 \pm 25.5 f$ \\
\hline 16 & Hyeseonmanchudae & $5.0 \pm 0.5 f g h$ & $171.5 \pm 5.9 b$ & $51.0 \pm 5.8 \mathrm{jk}$ & $438.1 \pm 12.2 \mathrm{~h}$ & $56.0 \pm 5.1 \mathrm{ijk}$ & $609.5 \pm 9.5 f$ \\
\hline 17 & Sambokhacheong & $5.0 \pm 0.5 f g h$ & $21.1 \pm 0.8 \mathrm{ij}$ & $103.2 \pm 5.3 c$ & $539.6 \pm 7.7 \mathrm{~h}$ & $108.2 \pm 4.7 d$ & $560.7 \pm 7.0 \mathrm{fg}$ \\
\hline 18 & Chunhachujeokchima & $25.9 \pm 2.2 b$ & $90.4 \pm 6.4$ de & $123.6 \pm 8.2 b$ & $521.6 \pm 29.6 h$ & $149.5 \pm 8.4 b$ & $612.1 \pm 29.3 f$ \\
\hline 19 & Yelpungjeokchima & $2.4 \pm 0.1 \mathrm{kl}$ & $72.6 \pm 13.2 f$ & $51.6 \pm 1.5 \mathrm{ijk}$ & $994.5 \pm 24.1 \mathrm{ef}$ & $54.0 \pm 1.1 \mathrm{jk}$ & $1067.1 \pm 26.4 \mathrm{de}$ \\
\hline 20 & Superseonpung & $1.8 \pm 0.21$ & $213 \pm 48.2 \mathrm{a}$ & $9.9 \pm 0.2 \mathrm{~m}$ & $3888.2 \pm 586.1 \mathrm{a}$ & $11.7 \pm 0.7 \mathrm{~m}$ & $4101.2 \pm 448.5 a$ \\
\hline 21 & Tomalin & $4.2 \pm 1.1 \mathrm{ghij}$ & $119.1 \pm 12.9 \mathrm{c}$ & $68.6 \pm 2.0 \mathrm{ef}$ & $985.6 \pm 183.8 \mathrm{ef}$ & $72.8 \pm 0.8 f g h$ & $1104.7 \pm 98.3 \mathrm{bcd}$ \\
\hline 22 & Cheongchima & $5.0 \pm 1.6 f g h i$ & $11.6 \pm 0.1 j$ & $60.1 \pm 9.9 \mathrm{ghij}$ & $211.5 \pm 19.3 i$ & $65.1 \pm 5.8 \mathrm{hij}$ & $223.1 \pm 4.9 h$ \\
\hline
\end{tabular}

Values are mean \pm standard deviation of biological triplicates. Different letters between rows indicate statistically significant differences at $\mathrm{p}<00.05$

S/No sample number

found to exhibit a significant variability based on variety in chicory and endive [42].

The content of lactucin and lactucopicrin in bolting stage leaves of lettuce are higher compared to the mature stage lettuce in this study as well as in previous study results $[3,15,41]$. All the cultivars considered in this study had higher lactucin (1.7- to 118.3-fold) and lactucopicrin (1.7- to 392.7-fold) concentrations at the bolting stage compared to their mature stage counterparts. The highest and least changes in the content of SLs were recorded in "Superseongpung" and "Sunredbutter" cultivars, respectively. The higher content of SLs at bolting stage compared to the mature stage could be attributed to de novo synthesis in new leaves generated at the latter stage as well as due to altered SLs expression in old leaves. Moreover, the older leaf tissues could accumulate more SLs through time. Literature concerning the relation between leaf age of lettuce and SLs are elusive. A similar observation to our result was reported in cultivated sunflower [43]. In another study, the total SLs concentration progressively increased as flowers of Arnica Montana get matured from buds to fully opened flowers and further increased as the petals withered [44].
Sweeter taste and more crispy texture of lettuce are the favorable sensory attributes for consumers [45]. Hence, sensory properties such as bitterness in part contribute to the overall acceptability of lettuce. The high content of SLs found in mature leaves as indicated in this study and flowering heads of plants [46] could diminish consumer acceptance.

ABTS assay, a method based on scavenging of the stable cation radical ABTS $\cdot{ }^{+}$, was used to estimate the antioxidant potential of methanol/water/formic acid extracts of lettuce. ABTS assay provides operational simplicity, diverse and flexible applicability in multiple media to determine both hydrophilic and lipophilic antioxidant potential of food extracts. In addition, as it presents absorbance peaks at 730 and $842 \mathrm{~nm}$, ABTS avoid interferences that could arise from pigments in the lettuce extract or secondary reaction products between the chromogen and samples [47]. Significant differences in the content of phenolic compounds and antioxidant activity between green, green/red and red varieties were detected. Figure 4 presents the ABTS radical scavenging potentials of lettuce cultivars at mature and bolting stages. The ABTS radical scavenging potential ranged 


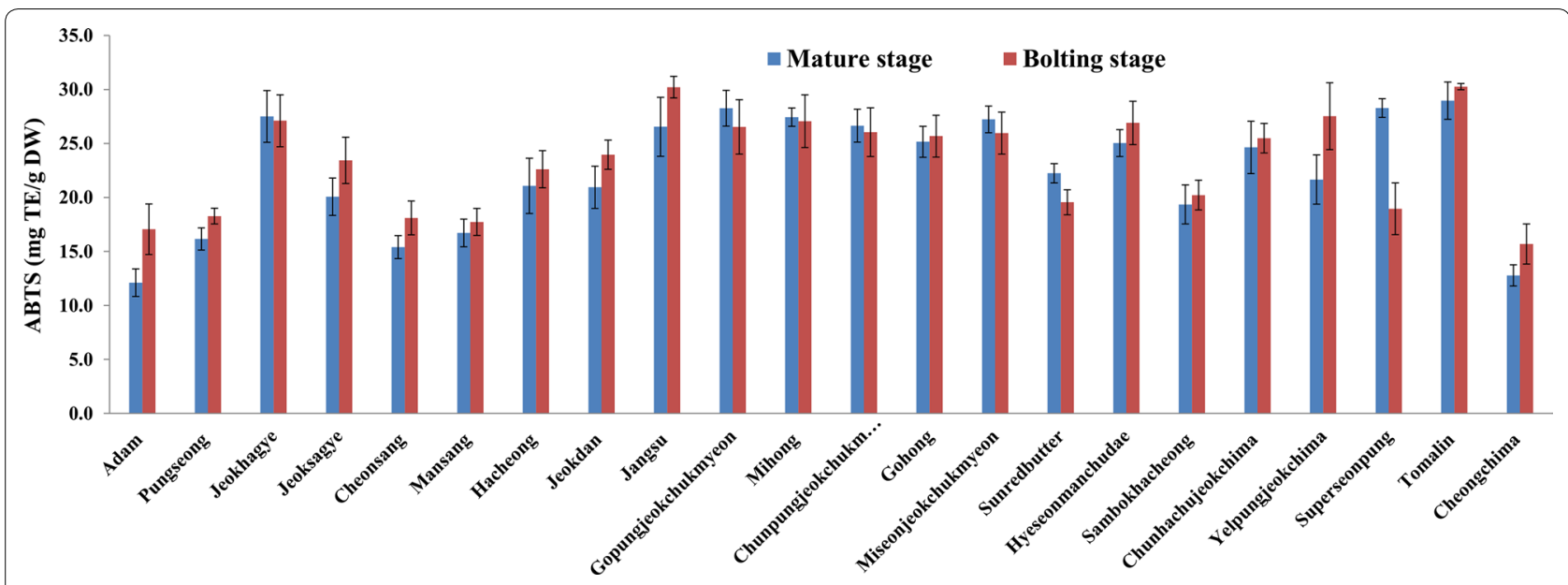

Fig. 4 ABTS radical scavenging potentials of lettuce cultivars at mature and bolting stages

from 12.1 to $29.0 \mathrm{mg} \mathrm{TE} / \mathrm{g} \mathrm{DW}$ and 15.7 to $30.3 \mathrm{mg} \mathrm{TE} / \mathrm{g}$ DW in mature stage and bolting stage lettuce leaves, respectively. The antioxidant activity of about $80 \%$ of the cultivars analyzed showed an increase (2.1 to $40.9 \%$ ) in ABTS radical scavenging potential with maturity. Unlike other cultivars, the ABTS radical scavenging potential of a red commercial cultivar "Superseonpung" was approximately $50 \%$ lower at bolting stage compared to mature stage of lettuce. Studies concerning the effect of the maturity stage on the antioxidant potential of lettuce are elusive. However, in the case of other vegetables, such as spinach, the oxygen radical absorbance capacity (ORAC) values were found to be higher at mid-maturity stage compared to immature and mature leaves [48]. In another study of pac choi, spinach, red leaf lettuce, and romaine lettuce, mature head stage showed higher ORAC values than at the baby-sized stage [49]. Green/red and red pigmented lettuce cultivars were superior in their ABTS radical scavenging potential compared with green pigmented cultivars. This was supported by the significant correlation (Pearson correlation coefficient, $\mathrm{R}=0.811$, at $p<0.01)$ between the cyanidin content and ABTS radical scavenging activity demonstrating that cyanidin contributes to the antioxidant capacity of lettuce. The higher antioxidant activity in the red and green/red pigmented cultivars could also be related to their relatively higher amount of phenolic compounds. In concordance with the results of this study, Pérez-López et al. [6] observed that the hydrophilic antioxidant capacity increased together with anthocyanins for red pigmented lettuce.

\section{Multivariate analysis}

Principal components analysis (PCA) is a procedure for finding hypothetical variables that account for as much of the variance in multidimensional data set as possible
[22]. In the PCA, a multivariate analysis was used in order to distinguish lettuce cultivars based on their leaf color (green, green/red, and red). Phenolic acids (3-CQA, 5-CQA, 5-FQA, DCTA), flavonoids (KGR, QMG, KMG, and MKGR), cyanidin, SLs (lactucin and lactucopicrin), and ABTS antioxidant activity data yielded three principal components with eigenvalues $\geq 1$ of the correlation matrix accounting collectively for $84.1 \%$ and $78.0 \%$ of the total variance in the dataset of the mature and bolting stage lettuce cultivars, respectively (Additional file 1: Appendix S1). In mature lettuce cultivars, Eigen analysis of the loadings of the two significant principal components (PC1 and $\mathrm{PC} 2$ ) revealed that $\mathrm{PC} 1$ (X-axis, Fig. 5a) was mainly contributed by 5-FQA, 5-CQA, and ABTS. Meanwhile, PC2 (Y-axis, Fig. 5a) was mostly contributed by DCTA and KGR. The first three variables which contribute most to PC1 (X-axis, Fig. 5b) in mature leaf cultivars were 5-FQA, lactucin, and cyanidin whereas 5-CQA, ABTS, and MKGR contributed highly to PC2 (Y-axis, Fig. 5b). The score and loading plot (Fig. 5) was generated based on leaf color which were classified as green (7), green/red (9), and red (6) based on visual assessment at the field and laboratory. As can be seen in Fig. 5, the green pigmented lettuce cultivars were clearly grouped in the negative side of the $\mathrm{X}$-axis (PC1) except cultivar "Hacheong" of the mature stage lettuce which was located at the upper left-hand quadrant of Fig. 5a. The isolation of "Hacheong" from other green pigmented cultivars of mature lettuce samples may be described by the significantly higher contents of DCTA and KGR compared with other green pigmented cultivars which are co-located in this region of the loading plot. All the red pigmented cultivars were located to the positive side of PC1 except the bolting stage leaves of "Superseonpung" cultivar which had significantly higher content of SLs 


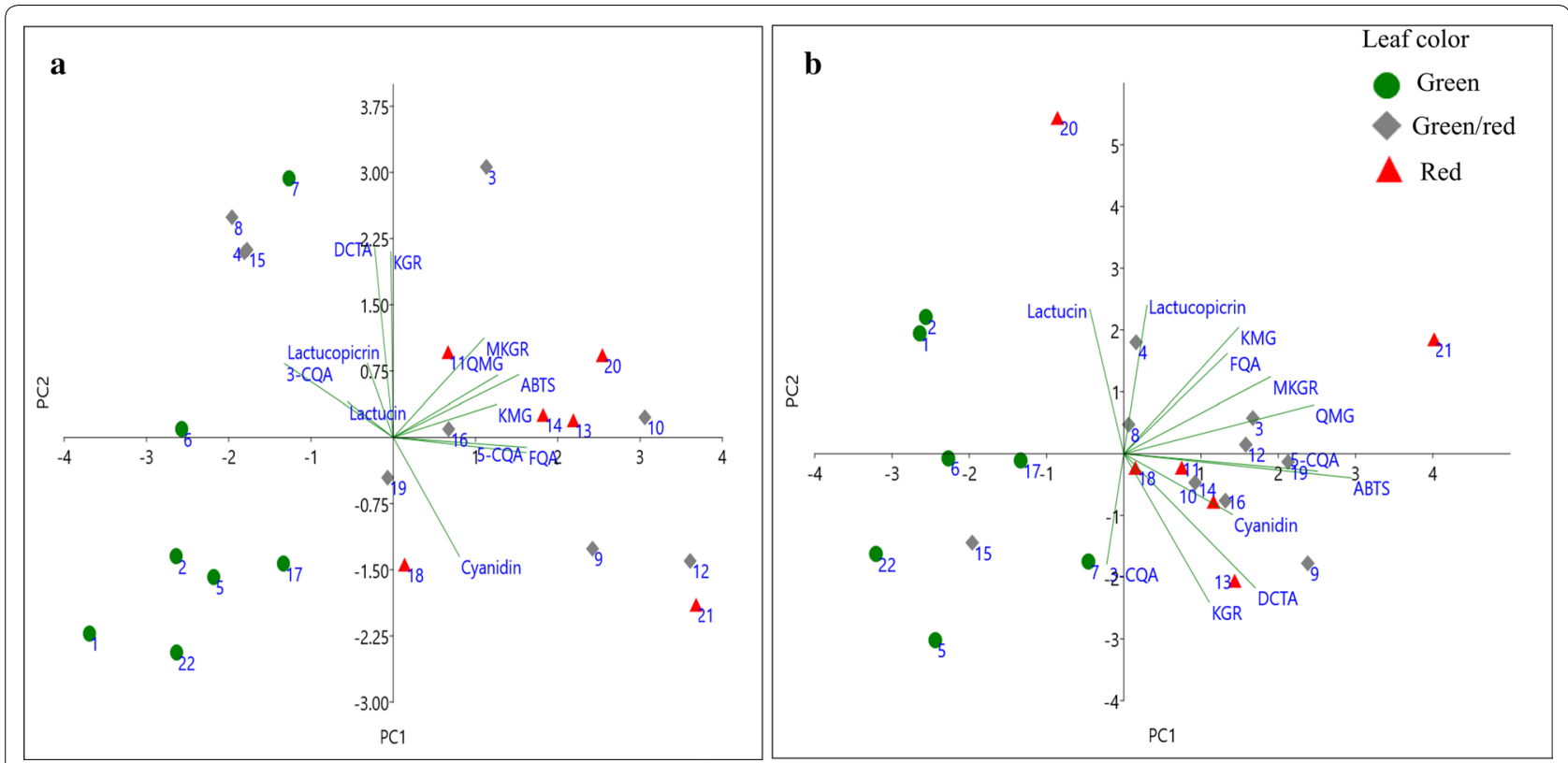

Fig. 5 The loading and score plot of 22 lettuce cultivars at mature stage (a) and bolting stage (b). The score plot was grouped using leaf color (green, green/red, and red). The numerals (1-22) correspond to the cultivars described in Table 2

compared with all other cultivars studied. The green/ red pigmented cultivars of mature stage lettuce were significantly distributed in all quadrants with no prominent groupings. In contrast, green/red pigmented bolting stage cultivars were grouped to the positive side of PC1 except "Sunredbutter" which was co-located with green pigmented cultivars at the bottom left-hand side of the quadrant. The loading plot showed that the phenolic acids, flavonoids, and cyanidin are positively correlated with ABTS, indicating that the compounds contribute to the radical scavenging activity of lettuce extracts. Bolting stage leaf samples of the cultivars "Superseopung" and "Tomalin" were different from other cultivars because they have significantly higher content of SLs and QMG compared with others cultivars, respectively. These observations suggested that leaf color could partly contribute to the distinct phytoconstituents profile of lettuce such as phenolic compounds and antioxidant potential. However, a correlation between leaf color and the SLs content of lettuce was not observed.

\section{Conclusions}

To summarize, we have identified, characterized and quantified the major phytochemicals (caffeoylquinic acids, dicaffeoylquinic acid, dicaffeoyltartaric acid, kaempferol conjugates, quercetin malonylglucoside, sesquiterpene lactones, and cyanidin) in 22 lettuce cultivars at mature and bolting stages using UPLC-PDAQ-TOF-HDMS, UPLC, and HPLC. Their antioxidant potential was also explored using ABTS radical scavenging assay. The composition and contents of the studied metabolites and antioxidant activity varied significantly and was principally depend on leaf color, cultivar type, and maturity. The main phenolic acid components of lettuce were quinic and tartaric acid derivatives, whereas kaempferol derivatives were the dominant flavonoids across the entire sample. Bolting stage lettuce leaves accumulate relatively high amount of sesquiterpene lactones and some phenolic compounds such as QMG, MGKR, KMG, and 3-CQA compared to mature stage. Red and green/red lettuces contain higher MGKR compared to green pigmented cultivars in bolting stage lettuce leaves. Red pigmented lettuce also exhibited higher antioxidant capacity compared to the green and green/red pigmented lettuce, suggesting that cyanidin contributed to the antioxidant potential of lettuce leaf. The red pigmented lettuce showed higher content of cyanidin proportional to the intensity of the pigment. However, the green pigmented lettuce lack detectable amount of cyanidin. The PCA, where the score and loading plots were generated according to leaf color of lettuce cultivars, showed a prominent grouping of green pigmented lettuce cultivars in the negative side of the X-axis (PC1) except cultivar "Hacheong" of the mature stage lettuce. All the red pigmented cultivars were located to the positive side of PC1 except the bolting stage leaf sample of "Superseonpung" cultivar which had significantly higher content of 
SLs. The green/red pigmented cultivars of the mature stage lettuce were significantly distributed in all quadrants with no prominent groupings. Overall, higher amount of phytoconstituents were found to be accumulated in the red pigmented lettuce leaves compared to the green lettuce leaves. In addition, the contents of most of the metabolites in lettuce seem to increase with age of the leaves. Due to the bitter nature of SLs, their presence in significantly high amount in lettuce leaves at bolting stage could diminish consumer acceptance. However, alternatively, these leaves could be utilized by nutraceutical companies working to recover these compounds (Additional file 2: Appendix S2).

\section{Additional files}

Additional file 1: Appendix S1. Loadings for the first three principal components (PC) of phenolic acids (3-CQA, 5-CQA, FQA, DCTA), flavonoids (KGR, QMG, KMG, and MKGR), cyanidin, SLs (lactucin and lactucopicrin), and antioxidant activity (ABTS).

Additional file 2: Appendix S2. Proposed chemical structures of identified compounds in the leaves of lettuce.

\section{Authors' contributions}

ADA, SC and JHR made a significant contribution to designing the experiment, analysis, drafting and writing the manuscript. JEL and JSS have made substantial contribution to collection and analysis of the data. OSH, NYR, and HSL have participated in conception, interpretation of data, proofreading and revising the manuscript. SWJ recorded the phenotypic data and provided the samples. All authors read and approved the final manuscript.

\section{Author details}

${ }^{1}$ National Agrobiodiversity Center, National Institute of Agricultural Sciences, RDA, Jeonju 54874, South Korea. ${ }^{2}$ Vegetable Research Division, National Institute of Horticultural \& Herbal Science, RDA, Wanju 55365, South Korea.

\section{Acknowledgements}

This research was carried out with the support of "Research Program for Agricultural Science \& Technology Development (Project NO. PJ01427701)", National Institute of Agricultural Sciences, Rural Development Administration, Republic of Korea.

\section{Competing interests}

The authors declare that they have no competing interests.

\section{Availability of data and materials}

All data and materials are fully available without restriction at the author's institutions.

\section{Ethics approval and consent to participate}

Not applicable.

\section{Funding}

The project was funded by National Institute of Agricultural Sciences, Rural Development Administration, Republic of Korea (Grant No. PJ01427701).

\section{Publisher's Note}

Springer Nature remains neutral with regard to jurisdictional claims in published maps and institutional affiliations.
Received: 5 November 2018 Accepted: 5 April 2019

Published online: 19 April 2019

\section{References}

1. Kim DE, Shang X, Assefa AD et al (2018) Metabolite profiling of green, green/red, and red lettuce cultivars: variation in health beneficial compounds and antioxidant potential. Food Res Int 105:361-370

2. Touliatos D, Dodd IC, Mcainsh M (2016) Vertical farming increases lettuce yield per unit area compared to conventional horizontal hydroponics. Food Energy Secur 5:184-191

3. Seo MW, Yang DS, Kays SJ et al (2009) Sesquiterpene lactones and bitterness in korean leaf lettuce cultivars. HortScience 44:246-249

4. Gazula A, Kleinhenz MD, Scheerens JC, Ling PP (2007) Anthocyanin levels in nine lettuce (Lactuca sativa) cultivars: influence of planting date and relations among analytic, instrumented, and visual assessments of color. HortScience 42:232-238

5. Llorach R, Martínez-Sánchez A, Tomás-Barberán FA et al (2008) Characterisation of polyphenols and antioxidant properties of five lettuce varieties and escarole. Food Chem 108:1028-1038

6. Pérez-López U, Pinzino C, Quartacci MF et al (2014) Phenolic composition and related antioxidant properties in differently colored lettuces: a study by Electron Paramagnetic Resonance (EPR) kinetics. J Agric Food Chem 62:12001-12007

7. Ribas-Agustí A, Gratacós-Cubarsí M, Sárraga C et al (2011) Analysis of eleven phenolic compounds including novel p-coumaroyl derivatives in lettuce (Lactuca sativa L.) by Ultra-high-performance Liquid Chromatography with photodiode array and mass spectrometry detection. Phytochem Anal 22:555-563

8. Lopez A, Javier G-A, Fenoll J et al (2014) Chemical composition and antioxidant capacity of lettuce: comparative study of regular-sized (Romaine) and baby-sized (Little Gem and Mini Romaine) types. J Food Compos Anal 33:39-48

9. Tamaki H, Robinson RW, Anderson JL, Stoewsand GS (1995) Sesquiterpene lactones in virus-resistant lettuce. J Agric Food Chem 43:6-8

10. Chon SU, Jang HG, Kim DK et al (2005) Allelopathic potential in lettuce (Lactuca sativa L.) plants. Sci Hortic (Amsterdam) 106:309-317

11. Pernice R, Scuderi D, Napolitano A et al (2007) Polyphenol composition and qualitative characteristics of fresh-cut lettuce in relation to cultivar, mulching, and storage. J Hortic Sci Biotechnol 82:420-427

12. Ferreres F, Gil MI, Castan M, Tomas-Barberan FA (1997) Phenolic metabolites in red pigmented lettuce (Lactuca sativa). Changes with minimal processing and cold storage. J Agric Food Chem 45:4249-4254

13. Bunning ML, Kendall PA, Stone MB et al (2010) Effects of seasonal variation on sensory properties and total phenolic content of 5 lettuce cultivars. J Food Sci 75:156-161

14. Gazula A, Kleinhenz MD, Streeter JG, Miller AR (2005) Temperature and cultivar effects on anthocyanin and chlorophyll b concentrations in three related lollo rosso lettuce cultivars. HortScience 40:1731-1733

15. Arakawa K, Minami M, Nakamura K et al (2009) Differences of sesquiterpene lactones content in different leaf parts and head formation stages in lettuce. Hortic Res 8:13-17

16. Yang X, Wei S, Liu B et al (2018) A novel integrated non-targeted metabolomic analysis reveals signi fi cant metabolite variations between different lettuce (Lactuca sativa L.) varieties. Hortic Res 5:1-14

17. Viacava GE, Gonzalez-Aguilar G, Roura SI (2014) Determination of phytochemicals and antioxidant activity in butterhead lettuce related to leaf age and position. J Food Biochem 38:352-362

18. Marin A, Ferreres F, Barbera GG, Gil MI (2015) Weather variability influences color and phenolic content of pigmented baby leaf lettuces throughout the season. J Agric Food Chem 63:1673-1681

19. Santos J, Oliveira MBPP, Ibanez E, Herrero M (2014) Phenolic profile evolution of different ready-to-eat baby-leaf vegetables during storage. J Chromatogr A 1327:1 18-131

20. Price KR, DuPont MS, Shepherd R et al (1990) Relationship between the chemical and sensory properties of exotic salad crops-coloured lettuce (Lactuca sativa) and chicory (Cichorium intybus). J Sci Food Agric 53:185-192 
21. Re R, Pellegrini N, Proteggente A et al (1999) Antioxidant activity applying an improved ABTS radical cation decolorization assay. Free Radic Biol Med 26:1231-1237

22. Hammer $\varnothing$, Harper DAT, Ryan PD (2001) PAST: paleontological statistics software package for education and data analysis. Palaeontol Electron 4:1-9

23. Assefa AD, Keum YS (2017) Effect of extraction solvent and various drying methods on polyphenol content and antioxidant activities of yuzu (Citrus junos Sieb ex Tanaka). J Food Meas Charact 11:576-585

24. Viacava GE, Roura SI, Berrueta LA et al (2017) Characterization of phenolic compounds in green and red oak-leaf lettuce cultivars by UHPLC-DADESI-QToF/MS using MS ${ }^{\mathrm{E}}$ scan mode. J Mass Spectrom 52:873-902

25. Hausler M, Ganzera M, Abel G et al (2002) Determination of caffeoylquinic acids and flavonoids in Cynara scolymus L. by High Performance Liquid Chromatography. Chromatographia 56:407-411

26. Schutz K, Kammerer D, Carle R, Schieber A (2004) Identification and quantification of caffeoylquinic acids and flavonoids from artichoke (Cynara scolymus L.) heads, juice, and pomace by HPLC-DAD-ESI/MSn. J Agric Food Chem 52:4090-4096

27. Clifford MN, Zheng W, Kuhnert N (2006) Profiling the chlorogenic acids of aster by HPLC-MSn. Phytochem Anal 17:384-393

28. Lin long Z, Harnly JM (2008) Identification of hydroxycinnamoylquinic acids of arnica flowers and burdock roots using a standardized LC-DADESI/MS profiling method. J Agric Food Chem 56:10105-10114

29. Jaiswal R, Sovdat T, Vivan F, Kuhnert N (2010) Profiling and characterization by LC-MS ${ }^{n}$ of the chlorogenic acids and hydroxycinnamoylshikimate esters in mate (Ilex paraguariensis). J Agric Food Chem 58:5471-5484

30. Clifford MN, Johnston KL, Knight S, Kuhnert N (2003) Hierarchical scheme for $\mathrm{LC}^{-M S^{n}}$ identification of chlorogenic acids. J Agric Food Chem 51:2900-2911

31. Pepe G, Sommella E, Manfra M et al (2015) Evaluation of anti-inflammatory activity and fast UHPLC-DAD-IT-TOF profiling of polyphenolic compounds extracted from green lettuce (Lactuca sativa L.; Var. Maravilla de Verano). Food Chem 167:153-161

32. Heimler D, Isolani L, Vignolini P et al (2007) Polyphenol content and antioxidative activity in some species of freshly consumed salads. J Agric Food Chem 55:1724-1729

33. Lech K, Witko K, Jarosz M (2014) HPLC-UV-ESI MS/MS identification of the color constituents of sawwort (Serratula tinctoria L.). Anal Bioanal Chem 406:3703-3708

34. Abu-reidah IM, Contreras MM, Arráez-román D (2013) Reversed-phase ultra-high-performance liquid chromatography coupled to electrospray ionization-quadrupole-time-of-flight mass spectrometry as a powerful tool for metabolic profiling of vegetables: Lactuca sativa as an example of its application. J Chromatogr A 1313:212-227
35. Dupont MS, Mondin Z, Williamson G, Price KR (2000) Effect of variety, processing, and storage on the flavonoid glycoside content and composition of lettuce and endive. J Agric Food Chem 48:3957-3964

36. Chon SU, Boo HO, Heo BG, Gorinstein S (2012) Anthocyanin content and the activities of polyphenol oxidase, peroxidase and phenylalanine ammonia-lyase in lettuce cultivars. Int J Food Sci Nutr 63:45-48

37. Wu X, Gu L, Prior RL et al (2004) Characterization of anthocyanins and proanthocyanidins in some cultivars of Ribes, Aronia, and Sambucus and their antioxidant capacity. J Agric Food Chem 5:7846-7856

38. De Pascual-Teresa S, Sanchez-Ballesta MT (2008) Anthocyanins: from plant to health. Phytochem Rev 7:281-299

39. Neill SO, Gould KS (2003) Anthocyanins in leaves: light attenuators or antioxidants? Funct Plant Biol 30:865-873

40. Graziani G, Ferracane R, Sambo P et al (2015) Profiling chicory sesquiterpene lactones by high resolution mass spectrometry. Food Res Int 67:193-198

41. Beharav A, Ben-David R, Malarz J et al (2010) Variation of sesquiterpene lactones in Lactuca aculeata natural populations from Israel, Jordan and Turkey. Biochem Syst Ecol 38:602-611

42. Ferioli F, Manco MA, Antuono LFD (2015) Variation of sesquiterpene lactones and phenolics in chicory and endive germplasm. J Food Compos Anal 39:77-86

43. Chou JC, Mullin CA (1993) Phenologic and tissue distribution of sesquiterpene lactones in cultivated sunflower (Helianthus annuus L.). J Plant Physiol 142:657-663

44. Douglas JA, Smallfield BM, Burgess EJ et al (2004) Sesquiterpene lactones in Arnica montana: a rapid analytical method and the effects of flower maturity and simulated mechanical harvesting on quality and yield. Planta Med 70:166-170

45. Pollard J, Kirk SFL, Cade JE (2002) Factors affecting food choice in relation to fruit and vegetable intake: a review. Nutr Res Rev 15:373

46. Chadwick M, Trewin H, Gawthrop F, Wagstaff C (2013) Sesquiterpenoids lactones: benefits to plants and people. Int J Mol Sci 14:12780-12805

47. Arnao MB (2000) Some methodological problems in the determination of antioxidant activity using chromogen radicals: a practical case. Trends Food Sci Technol 11:419-421

48. Pandjaitan N, Howard LR, Morelock T, Gil MI (2005) Antioxidant capacity and phenolic content of spinach as affected by genetics and maturation. J Agric Food Chem 53:8618-8623

49. Zhao X, Iwamoto T, Carey EE (2007) Antioxidant capacity of leafy vegetables as affected by high tunnel environment, fertilisation and growth stage. J Sci Agric 87:2692-2699
Ready to submit your research? Choose BMC and benefit from:

- fast, convenient online submission

- thorough peer review by experienced researchers in your field

- rapid publication on acceptance

- support for research data, including large and complex data types

- gold Open Access which fosters wider collaboration and increased citations

- maximum visibility for your research: over $100 \mathrm{M}$ website views per year

At $\mathrm{BMC}$, research is always in progress.

Learn more biomedcentral.com/submissions 